\title{
Lethal multiple pterygium syndrome
}

INSERM

\section{Source}

INSERM. (1999). Orphanet: an online rare disease and orphan drug data base. Lethal multiple pterygium syndrome. ORPHA:33108

Lethal multiple pterygium syndrome (LMPS) is a rare association of anomalies of the skin, muscles and skeleton. 